\title{
Supramolecular composites of photocured acrylated epoxidized soybean oil and fibers formed by the self-assembly of low molecular weight organic gelators
}

\author{
Mitsuhiro Shibata, Katsuyuki Kaneko and Takuya Kakihara
}

A mixture of acrylated epoxidized soybean oil (AESO) with $\mathrm{N}$-carbobenzyloxy-L-isoleucylaminooctadecane (CIA) or (R)-12hydroxystrearic acid (HSA) containing photoinitiators was heated to $130^{\circ} \mathrm{C}$ and gradually cooled to room temperature to give bio-based gelatinous material. The photocuring of the AESO/CIA gel afforded a supramolecular composite composed of crosslinked AESO (cAESO) and self-assembled CIA fibers, whereas HSA crystallized in the case of the photocuring of AESO/HSA gel. Normal and polarized optical micrographic analysis revealed that a fibrous network and plate-like crystals are formed for CAESO/CIA and CAESO/HSA, respectively. The differential scanning calorimetry analysis confirmed the formation of a mesogenic phase of CIA molecules for CAESO/CIA and a crystalline phase of HSA for CAESO/HSA. The tensile strength and modulus at $20^{\circ} \mathrm{C}$ for CAESO/CIA increased with CIA content, whereas that of CAESO/HSA decreased with HSA content.

Polymer Journal (2011) 43, 552-558; doi:10.1038/pj.2011.36; published online 27 April 2011

Keywords: acrylated epoxidized soybean oil; biocomposites; hydroxystearic acid; isoleucine; low molecular weight organic gelator; self-assembly; supramolecular fiber

\section{INTRODUCTION}

Bio-based polymer products derived from annually renewable agricultural and biomass feedstock have become increasingly important as sustainable and eco-efficient products, which can replace products, based exclusively on petroleum feedstock. ${ }^{1-3}$ Triglyceride plant oils are a major class of such renewable resources. Soybean oil (SBO) is the most readily available and one of the least expensive vegetable oils in the world. In the past decade, much effort has been dedicated to producing SBO-based polymeric materials. ${ }^{4,5}$ Acrylate epoxidized soybean oil (AESO) is manufactured by the reaction of acrylic acid and ESO, which is produced by the epoxidation of the double bonds of the SBO triglycerides with hydrogen peroxide, either in acetic acid or in formic acid. ${ }^{6,7}$ AESO has been used as a reactive modifier, UVcuring ink and coating compositions. Nanocomposites with layered silicate $^{8-10}$ and biocomposites with natural fibers, ${ }^{11-13}$ environmentally benign reinforcing methods of expanding the application range of AESO, have been the subject of many recent publications. Wilder et al. ${ }^{14}$ reported dental composites composed of photocured ethoxylated bisphenol A dimethacrylate and dibenzylidene sorbitol as a low molecular weight organic gelator. However, the structure of selfassembled dibenzylidene sorbitol in the crosslinked resin had not been elucidated. We have already reported a new reinforcing method for photocured ESO, using a self-assembled (R)-12-hydroxystearic acid (HSA) nanofibrous network. ${ }^{15}$ HSA is an industrially available organic compound that is derived from bio-based castor oil and used as a low molecular weight organic gelator for cooking oils. ${ }^{16-20}$ Other low molecular weight organic gelators such as the amino acidbased gelators $N$-carbobenzyloxy-L-isoleucylaminooctadecane (CIA), $N$-lauroyl---glutamic acid- $\alpha, \gamma$-bis $(n$-butylamide $)$ and $N^{\alpha}$-acetyl$N^{\varepsilon}$-dodecyl--L-lysine are environmentally benign and inexpensive gelators. $^{21-23}$

The present work describes supramolecular composites of photocured AESO (cAESO) and fibers formed by the self-assembly of CIA. The morphological, thermal and mechanical properties of cAESO/CIA were investigated with respect to those of cAESO/HSA (Scheme 1). Our attention is also focused on the difference between the reinforcement effects of HSA and CIA.

\section{EXPERIMENTAL PROCEDURE}

Materials

AESO was purchased from Sigma-Aldrich Japan (Tokyo, Japan). HSA was supplied by Itoh Oil Chemicals (Yokkaichi, Japan). CIA was synthesized from $N$-carbobenzyloxy-L-isoleucine and 1 -aminooctadecane using $N, N^{\prime}$-dicyclohexylcarbodiimide as described in the literature. ${ }^{21}$ Photoinitiators, 1-hydroxycyclohexyl phenyl ketone (IRGACURE 184, mp. 45-49 ${ }^{\circ} \mathrm{C}$ ) and phenylbis (2,4,6-trimethylbenzoyl)phosphine oxide (IRGACURE 819, mp. 127-133 ${ }^{\circ} \mathrm{C}$ ) were supplied by Chiba Specialty Chemicals KK (Tokyo, Japan). All other chemicals used in this work were of reagent grade and used without further purification. 


\section{Preparation of SBO/HSA and SBO/CIA organogels}

As a control, SBO organogel containing HSA 10 parts per hundred parts by weight of resin (p.h.r.) or CIA 10 p.h.r. was prepared as follows: A mixture of SBO $(10.0 \mathrm{~g})$ with HSA or CIA $(1.00 \mathrm{~g})$ was heated at $\sim 130^{\circ} \mathrm{C}$ for $30 \mathrm{~min}$. The obtained homogenous solution was cooled under an ambient atmosphere for $1 \mathrm{~h}$ to give a gelatinous material of SBO/HSA or SBO/CIA containing HSA 10 p.h.r. or CIA 10 p.h.r. (SBO/HSA10 or SBO/CIA10), respectively.

For optical micrographic analysis, a few drops of the hot solution of SBO/ HSA or SBO/CIA were cast onto a glass plate. The obtained film was heated to $130^{\circ} \mathrm{C}$ on the hot stage attached to a microscope, held at that temperature for $3 \mathrm{~min}$ and cooled to room temperature at a cooling rate of $1{ }^{\circ} \mathrm{C} \mathrm{min}^{-1}$.

Preparation of photocured AESO/CIA and AESO/HSA composites A mixture of AESO (3.00 g), CIA (0.300 g), IRGACURE $184(0.030 \mathrm{~g})$ and IRGACURE $819(0.006 \mathrm{~g})$ was heated to $130^{\circ} \mathrm{C}$ and stirred for $15 \mathrm{~min}$ to yield a homogeneous liquid. A mass of $\sim 2.5 \mathrm{~g}$ of the hot oily substance was poured onto a $\Phi 55-\mathrm{mm}$ aluminum pan and allowed to stand at room temperature to give a gelatinous material. The obtained gel was photoirradiated under ice cooling for a total of $10 \mathrm{~min}$ at 15-s intervals to give a photocured AESO/CIA with CIA content of 5 p.h.r. (cAESO/CIA5) film (thickness: $\sim 1.0 \mathrm{~mm}$ ). A SPOT-CURE SP-7 (250 W light source, wavelength 240-440 nm, Ushio, Yokohama, Japan) device equipped with a uniform radiation-optical unit was used for UV curing (irradiation distance $200 \mathrm{~mm}$, irradiation intensity $77.6 \mathrm{~mW} \mathrm{~cm}^{-2}$ ). In a similar manner, the photocured AESO film without CIA and cAESO/HSA with a HSA content of 5 and 10 p.h.r. (cAESO/HSA5 and cAESO/HSA10) was prepared.

\section{Measurements}

FT-IR spectra were measured on a FT-IR 8100 spectrometer (Shimadzu, Kyoto, Japan) by the attenuated total reflection method. Differential scanning calorimetry (DSC) was performed using a differential scanning calorimeter, Pyris 1 (Perkin-Elmer Japan, Yokohama, Japan) under nitrogen atmosphere. The DSC sample was weighed $(\sim 10 \mathrm{mg})$ on a small aluminum pan, and the pan was then sealed. The sample was heated from room temperature to $140^{\circ} \mathrm{C}$ at a heating rate of $20^{\circ} \mathrm{C} \mathrm{min}^{-1}$, held at $140^{\circ} \mathrm{C}$ for $5 \mathrm{~min}$, subsequently cooled to $25^{\circ} \mathrm{C}$ at a cooling rate of $1{ }^{\circ} \mathrm{C} \mathrm{min}-1$ and then heated to $140^{\circ} \mathrm{C}$ at a heating rate of $20^{\circ} \mathrm{C} \mathrm{min}^{-1}$. Dynamic mechanical analysis of the rectangular specimen $\left(30 \times 5 \times 1 \mathrm{~mm}^{3}\right)$, cut from the photocured disk, was performed on a Rheolograph Solid (Toyo Seiki, Tokyo, Japan) device with a chuck distance of $20 \mathrm{~mm}$, a frequency of $1 \mathrm{~Hz}$ and a heating rate of $20^{\circ} \mathrm{C} \mathrm{min}^{-1}$, based on ISO 67214:1994 (Plastics-Determination of dynamic mechanical properties, Part 4:tensile vibration-non-resonance method). Polarized and normal optical microscopy was performed on an Olympus BXP microscope equipped with crossed polars, a CCD-IRIS color video camera (Sony Corporation, Tokyo, Japan) interfaced to a computer and a hot-stage RH-350 (Japan High Tech Fukuoka,
Japan). A few drops of hot solution of AESO/CIA (or AESO/HSA) were placed on a glass plate, and the resulting thin film was heated to $130^{\circ} \mathrm{C}$ on the hot stage, held at that temperature for $3 \mathrm{~min}$ and cooled to room temperature at a cooling rate of $1{ }^{\circ} \mathrm{Cmin}^{-1}$. The obtained thin gel on the glass plate was photoirradiated under the same conditions as those used for the preparation of cAESO/CIA and then subjected to micrographic observation. Flexural testing of the rectangular specimen $\left(30 \times 5 \times 1 \mathrm{~mm}^{3}\right)$ was performed using an Autograph AG-1 (Shimadzu). The span length was $20 \mathrm{~mm}$, and the testing speed was $1 \mathrm{~mm} \mathrm{~min}{ }^{-1}$. Five specimens were tested for each set of samples, and the mean values were calculated.

\section{RESULTS AND DISCUSSION}

Characterization of CAESO/HSA and CAESO/CIA by means of DSC analysis

The mixtures of AESO/HSA and AESO/CIA containing photoinitiators, which were homogeneous liquids at $130^{\circ} \mathrm{C}$, became gelatinous materials when cooled to room temperature. Photoirradiation of the AESO/HSA and AESO/CIA gels for 5-10 min produced cAESO/HSA and cAESO/CIA composites. As the FT-IR spectra of the AESO/ HSA10 and AESO/CIA10 gels photoirradiated for 5 min were largely the same as those of the corresponding samples photoirradiated for $10 \mathrm{~min}$, the photocuring time was fixed to $10 \mathrm{~min}$. In the IR spectra of AESO, the absorption peaks at 1408 and $810 \mathrm{~cm}^{-1}$ correspond to the in-plane and out-of-plane bending of acryl $\mathrm{C}-\mathrm{H}$ bonds. The absorption peaks related to the acryl group largely diminished in the FT-IR spectra of the cAESO, cAESO/HSA10 and cAESO/CIA10 samples, indicating the progress of the crosslinking reaction (Figure 1). However, the remaining peaks of cAESO/HSA10 and cAESO/CIA10 were slightly stronger than those of CAESO, suggesting that the crosslinking reaction is somewhat disturbed by the HSA and CIA gels. The remaining peak did not disappear with prolonged photoirradiation.

Figure 2 shows the FT-IR spectra of cAESO, cAESO/HSA5, cAESO/ HSA10 and HSA in the regions of $4000-2500 \mathrm{~cm}^{-1}$ and 2000 $1500 \mathrm{~cm}^{-1}$. The FT-IR spectrum of HSA showed the typical absorption bands at 3321 and $3222 \mathrm{~cm}^{-1}$ ( $\mathrm{vO}-\mathrm{H}$ of hydroxy and carboxy groups with intermolecular hydrogen bonding interaction), and $1699 \mathrm{~cm}^{-1}$ ( $\mathrm{vC}=\mathrm{O}$ of carboxy group). The corresponding absorption bands of the HSA component for cAESO/HSA5 and cAESO/HSA10 shifted to a slightly lower wavenumber region, suggesting that the hydrogen bonding interaction of cAESO/HSA composites is slightly stronger than that of crystalline HSA.

Figure 3 shows the FT-IR spectra of CIA, cAESO, cAESO/CIA5 and CAESO/CIA10 in the region of $1800-1500 \mathrm{~cm}^{-1}$. The absorption<smiles>C=CC(=O)OC(CCCCCCCC)C(O)CCCCCCCCC(=O)OCC(COC(=O)CCCCCCCC(O)C(CCCCCCCCC)OC(=O)C=C)OC(=O)CCCCCCCC(OC(=O)C=C)C(O)CC(O)C(CCCCC)OC(=O)C=C</smiles>

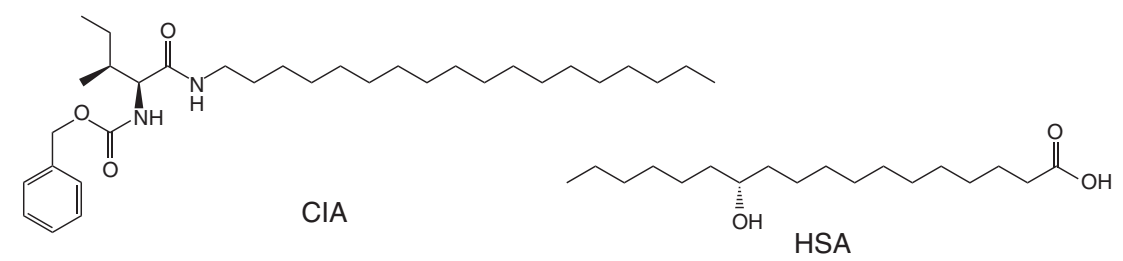

Scheme 1 Probable structure of AESO and the structure of $N$-carbobenzyloxy-L-isoleucylaminooctadecane $(\mathrm{CIA})$ and $(R)$-12-hydroxystrearic acid (HSA). 
bands at $1690 \mathrm{~cm}^{-1}\left(\mathrm{vC}=\mathrm{O}\right.$ of urethane) and $1647 \mathrm{~cm}^{-1}(\mathrm{vC}=\mathrm{O}$ of amide I) for CIA shifted considerably to a lower wavenumber region (1650-1647 and $1630-1627 \mathrm{~cm}^{-1}$ ) for cAESO/CIA5 and cAESO/ CIA10. On the other hand, the absorption bands at $1564 \mathrm{~cm}^{-1}$ $(\delta \mathrm{N}-\mathrm{H}$ of amide $\mathrm{II})$ and $1539 \mathrm{~cm}^{-1}(\delta \mathrm{N}-\mathrm{H}$ of urethane) for CIA shifted to a higher wavenumber region $\left(1578-1574 \mathrm{~cm}^{-1}\right)$ for cAESO/

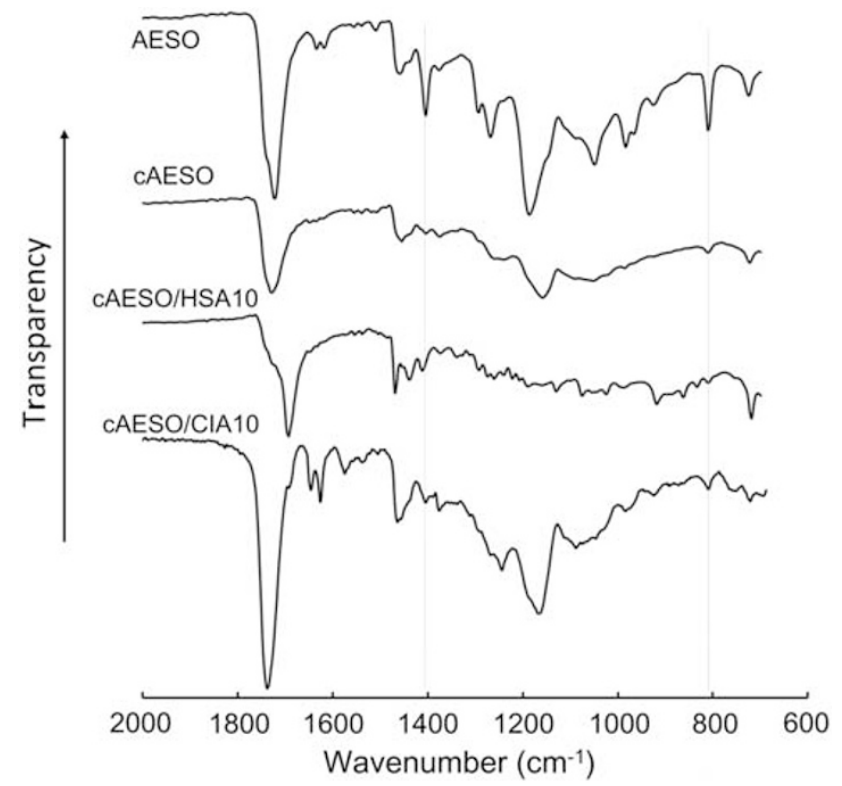

Figure 1 FT-IR spectra of acrylated epoxidized soybean oil (AESO) and the crosslinked AESO (CAESO), cAESO/(R)-12-hydroxystrearic acid (HSA)10 and CAESO/CIA10 samples that were photoirradiated for $10 \mathrm{~min}$.

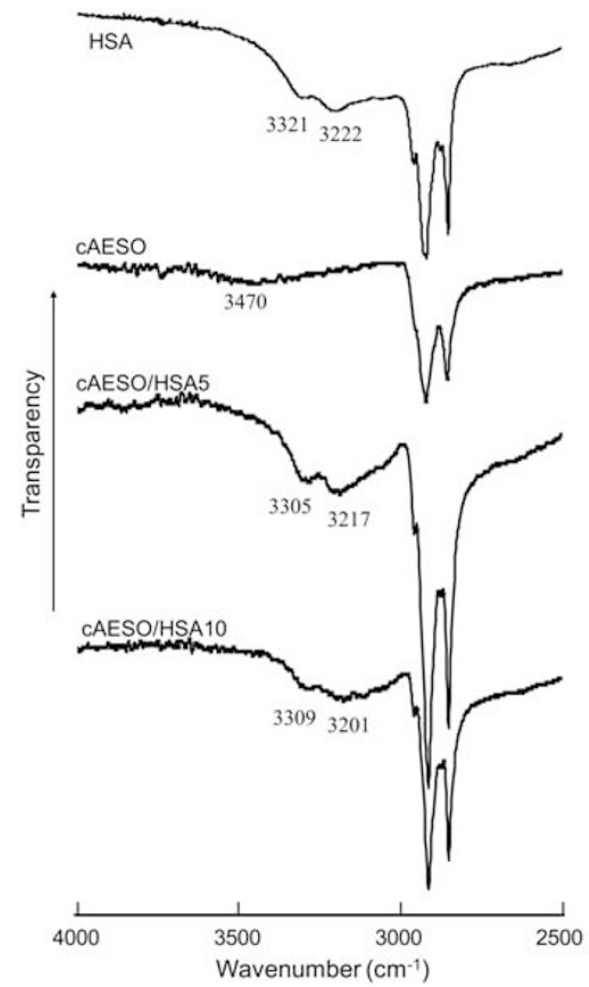

CIA composites. A similar shift of the amide I and amide II absorption bands has been reported for some amino acid-based organogelators. $^{23,24}$ These results indicate that there are strong intermolecular hydrogen-bonding interaction between $\mathrm{C}=\mathrm{O}$ and $\mathrm{NH}$ of amide and urethane groups in CIA molecules for cAESO/CIAs.

Figure 4 shows the first-heating DSC thermograms of AESO, AESO/ HSA gels and cAESO/HSA composites. The gelatinous AESO/HSA5 and AESO/HSA10 showed a thermal transition at $55.2^{\circ} \mathrm{C}(\Delta H=65.2 \mathrm{~J}$ per g HSA $)$ and $56.6^{\circ} \mathrm{C}(\Delta H=63.8 \mathrm{~J}$ per $\mathrm{g}$ HSA $)$. The temperature and enthalpy change of the thermal transition were considerably lower than $T_{\mathrm{m}}=81.1^{\circ} \mathrm{C}$ and $\Delta H_{\mathrm{m}}=117 \mathrm{~J}$ per $\mathrm{g}$ HSA of crystalline HSA, indicating that the thermal transition is not due to the melting of the crystalline phase but due to the isotropization of the mesophase composed of HSA aggregates. The reason why the enthalpy change is much smaller should be attributed to the fact that the mesophase is thermodynamically unstable compared with the perfect crystal. In addition, in fibers with tiny dimensions, the free surface energy has an important role and decreases the measured enthalpy change of the fibrillar aggregates. The isotropization temperatures $\left(T_{\mathrm{i}} \mathrm{s}\right)$ observed for ASEO/HSA5 and ASEO/HSA10 shifted to a higher temperature region $\left(75.8\right.$ and $\left.78.4{ }^{\circ} \mathrm{C}\right)$ after photocuring, which is close to $T_{\mathrm{m}}$ of HSA, indicating that the self-assembled HSA aggregates are densely packed and almost transform into the crystalline phase.

Figure 5 shows the first-heating DSC thermograms of AESO, AESO/ CIA gels and cAESO/CIA composites. The $T_{\mathrm{i}} \mathrm{s}$ of gelatinous AESO/ CIA5 and AESO/CIA10 were observed at $66.2(\Delta H=46.3 \mathrm{~J}$ per g CIA $)$ and $71.4^{\circ} \mathrm{C}(\Delta H=66.4 \mathrm{~J}$ per g CIA $)$, respectively. The $T_{\mathrm{i}} \mathrm{s}$ (95.3 and $98.1^{\circ} \mathrm{C}$ ) of cAESO/CIA5 and cAESO/CIA10 were higher than those of AESO/CIA5 and 10, whereas they were still much lower than $T_{\mathrm{m}}$ of CIA $\left(119.8^{\circ} \mathrm{C}\right)$, suggesting that the self-assembled CIA mesophase is maintained after photocuring. However, the $\Delta H s$ (15.0 and

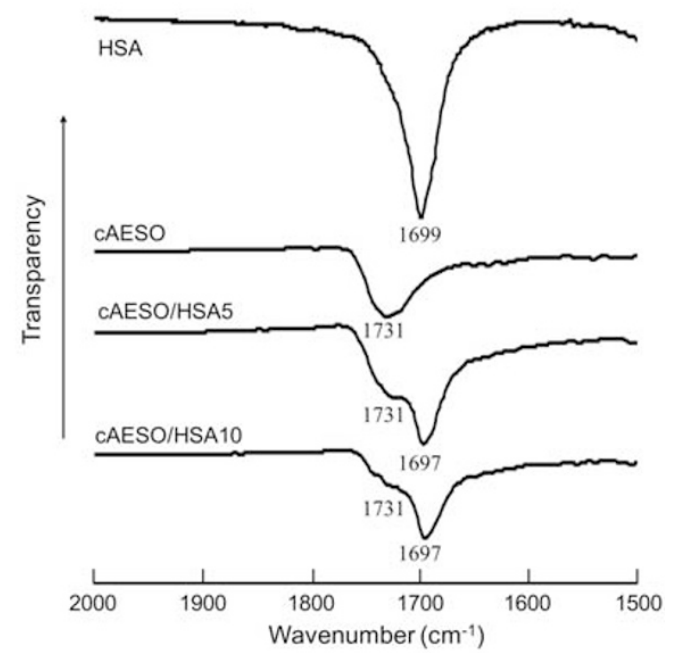

Figure 2 FT-IR spectra of crosslinked AESO (CAESO), cAESO/(R)-12-hydroxystrearic acid (HSA)5, cAESO/HSA10 and HSA in the regions of 4000$2500 \mathrm{~cm}^{-1}$ and $2000-1500 \mathrm{~cm}^{-1}$. 


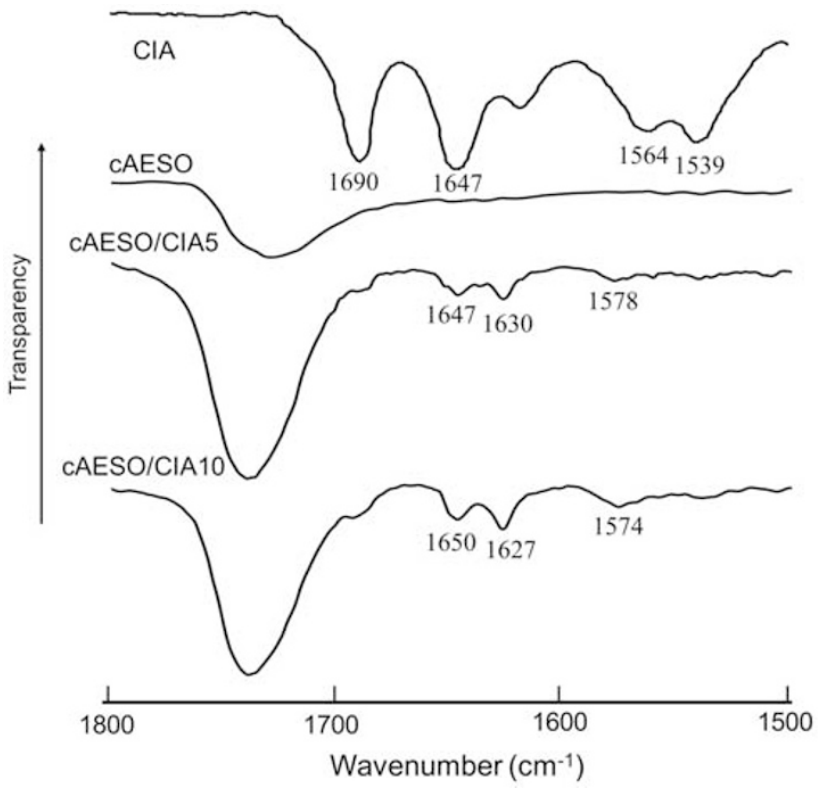

Figure 3 FT-IR spectra of crosslinked AESO (CAESO), cAESO/N-carbobenzyloxyL-isoleucylaminooctadecane (CIA)5, CAESO/CIA10 and CIA in the region of $1800-1500 \mathrm{~cm}^{-1}$.

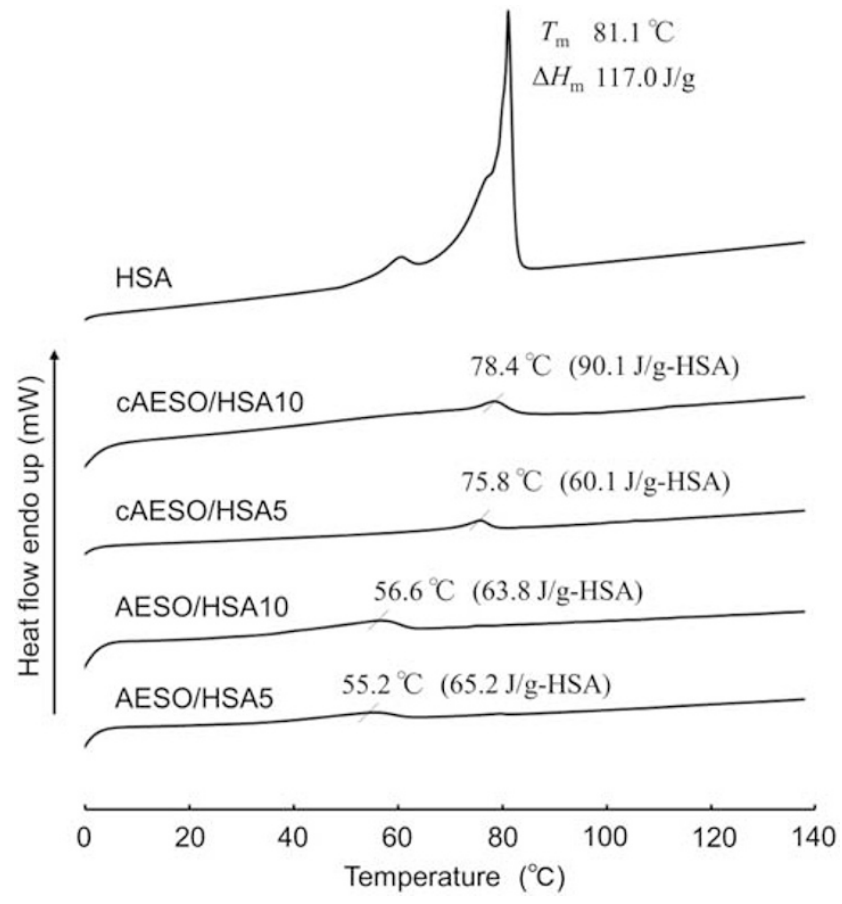

Figure 4 The first-heating differential scanning calorimetry (DSC) thermograms of $(R)$-12-hydroxystrearic acid (HSA), acrylated epoxidized soybean oil (AESO)/HSA gels and crosslinked AESO (cAESO)/HSA composites.

36.6 J per g CIA) of isotropization for CAESO/CIA5 and CAESO/CIA10 were much lower than those of AESO/CIA5 and AESO/CIA10, suggesting that considerable amounts of CIA dissolved in the crosslinked AESO. The $T_{\mathrm{i}} \mathrm{s}$ of cAESO/CIA5 and cAESO/CIA10 in the second-heating thermograms after cooling from $140{ }^{\circ} \mathrm{C}$ at a rate of $1^{\circ} \mathrm{C} \mathrm{min}{ }^{-1}$ were $108.3(\Delta H=8.04 \mathrm{~J}$ per $\mathrm{g}$ CIA $)$ and $111.0^{\circ} \mathrm{C}(\Delta H=17.3 \mathrm{~J}$ per g CIA $)$,

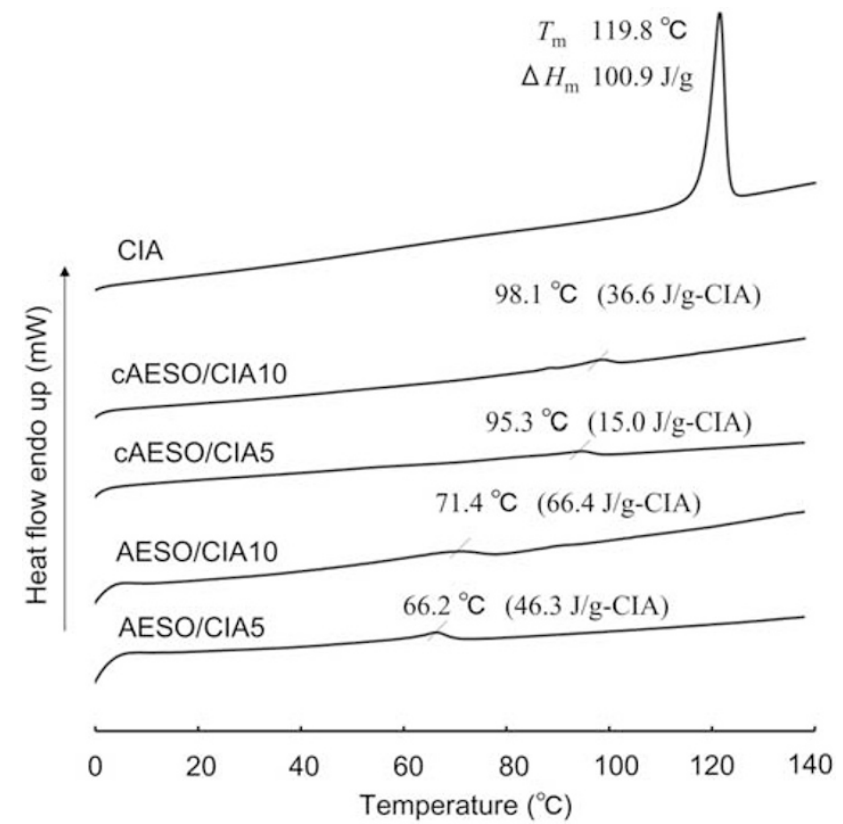

Figure 5 The first-heating differential scanning calorimetry (DSC) thermograms of $\mathrm{N}$-carbobenzyloxy-L-isoleucylaminooctadecane (CIA), acrylated epoxidized soybean oil (AESO/CIA gels and crosslinked AESO (CAESO)/CIA composites.

respectively. Their $T_{\mathrm{i}} \mathrm{s}$ were higher than the corresponding $T_{\mathrm{i}} \mathrm{s}$ during the first-heating process, and were still lower than $T_{\mathrm{m}}$ of CIA, indicating that the CIA mesophase is regenerated during the second heating, whereas the self-assembled structure becomes more similar to the CIA crystalline structure.

\section{Micrographic observation of cAESO/HSA and cAESO/CIA}

Figure 6 shows polarized and normal optical photomicrographs of the typical crystalline morphology of HSA and CIA and the fibrous network of SBO/HSA10 and SBO/CIA10 gels. The HSA and CIA started to crystallize at $\sim 70$ and $100{ }^{\circ} \mathrm{C}$ from the melt, and had a strong crystalline texture when observed under polarized light. The formed crystals were not fibrous materials, as is obvious from the normal optical micrograph. Typical organogels of SBO/HSA10 and SBO/CIA10 displayed birefringence to some extent under polarized light, and a dendritic fibrous network was formed as is shown in the normal optical micrograph.

Figure 7 shows polarized and normal optical photomicrographs of AESO/HSA10, cAESO/HSA10, AESO/CIA10 and cAESO/CIA10. The fibrous network of AESO/HSA10 gel was not dendritic as shown in the micrograph of SBO/HSA gel, but showed a randomly developed structure. However, when AESO/HSA10 gel was photocured, most of the fibrous networks disappeared in the normal optical micrograph of cAESO/HSA 10 and the mesogenic texture changed to a crystallinelike texture under polarized light. This result is in agreement with the fact that cAESO/HSA10 showed melting endothermal peak in the DSC analysis. On the other hand, a fibrous network similar to that of the SBO/CIA gel was observed for both AESO/CIA10 and cAESO/CIA10. The fact that cAESO/CIA has a supramolecular fibrous network is in marked contrast to heterogeneous crystalline HSA aggregates of cAESO/HSA. The difference is attributed to the higher affinity of CIA with cAESO than that of HSA, as is supported by the fact that the $\Delta H$ of isotropization of cAESO/CIA is much lower than that of cAESO/HSA. 


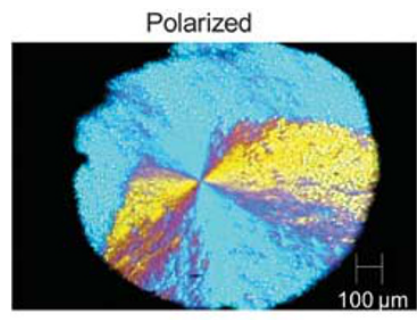

HSA

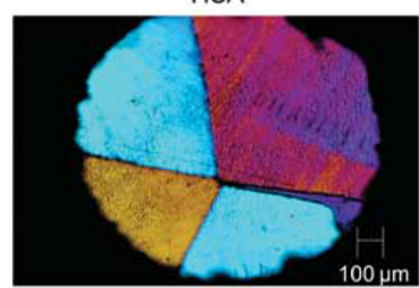

CIA

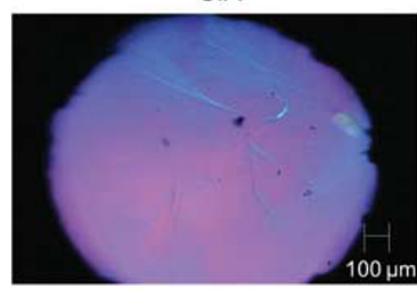

SBO/HSA10

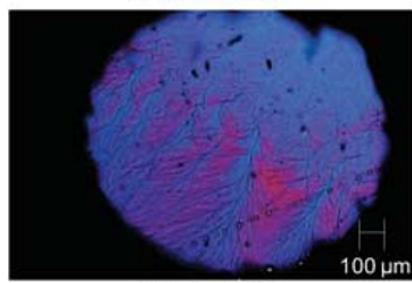

$\mathrm{SBO} / \mathrm{ClA} 10$

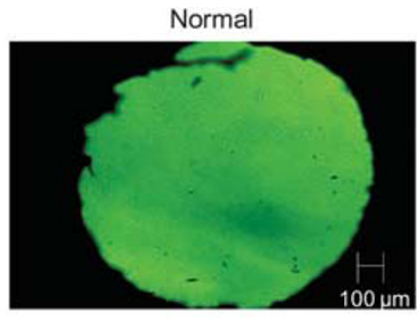

HSA

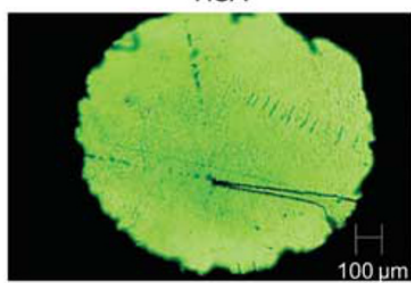

$\mathrm{CIA}$

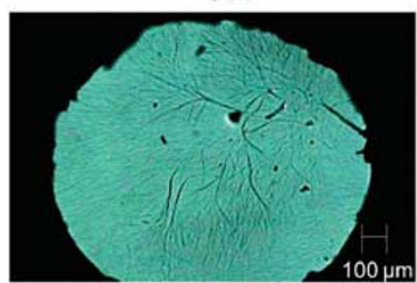

$\mathrm{SBO} / \mathrm{HSA} 10$

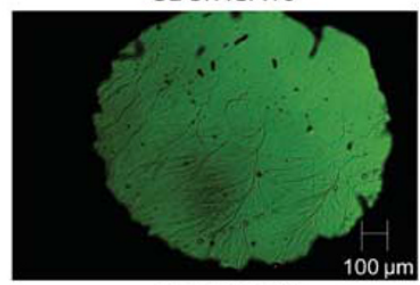

$\mathrm{SBO} / \mathrm{CIA} 10$

Figure 6 Polarized and normal optical photomicrographs of crystalline $(R)$ 12-hydroxystrearic acid (HSA) and $N$-carbobenzyloxy-L-isoleucylaminooctadecane (CIA), and gelatinous soybean oil (SBO)/HSA10 and SBO/CIA10 at room temperature after cooling from $130^{\circ} \mathrm{C}$ at a rate of $-1{ }^{\circ} \mathrm{C} \mathrm{min}-1$.

Figure 8 shows polarized and normal optical photomicrographs of cAESO/CIA10 at room temperature after the second cooling from $130{ }^{\circ} \mathrm{C}$ at a rate of $-1{ }^{\circ} \mathrm{Cmin}^{-1}$. The normal optical micrograph shows that the fibrous network is radially expanded and some fibers are thicker than those of the original cAESO/CIA10 shown in Figure 7. The radial morphology in the polarized micrograph somewhat resembles the crystalline morphology of CIA shown in Figure 6, in agreement with the result of the second-heating DSC thermogram.

\section{Mechanical properties of cAESO/HSA and cAESO/CIA}

Figure 9 shows dynamic mechanical analysis charts of cAESO, cAESO/ HSA and cAESO/CIA. The $\tan \delta$ peak temperature corresponding to the glass transition temperature for cAESO/HSA5 and 10 (36.2 and $38.1^{\circ} \mathrm{C}$ ) and CAESO/CIA5 and 10 (31.3 and $\left.28.2^{\circ} \mathrm{C}\right)$ was lower than that of $\operatorname{cAESO}\left(44.2^{\circ} \mathrm{C}\right)$. The lowering of glass transition temperature for cAESO/HSA and cAESO/CIA relative to cAESO is related to a part of the retardation of photocrosslinking reaction of AESO by HSA and CIA, as shown in the FT-IR analysis. The fact that glass transition temperature of CAESO/CIA was lower than that of cAESO/HSA shows that the amount of CIA dissolved in CAESO is greater than that of HSA, as is also obvious from the difference in $\Delta H$
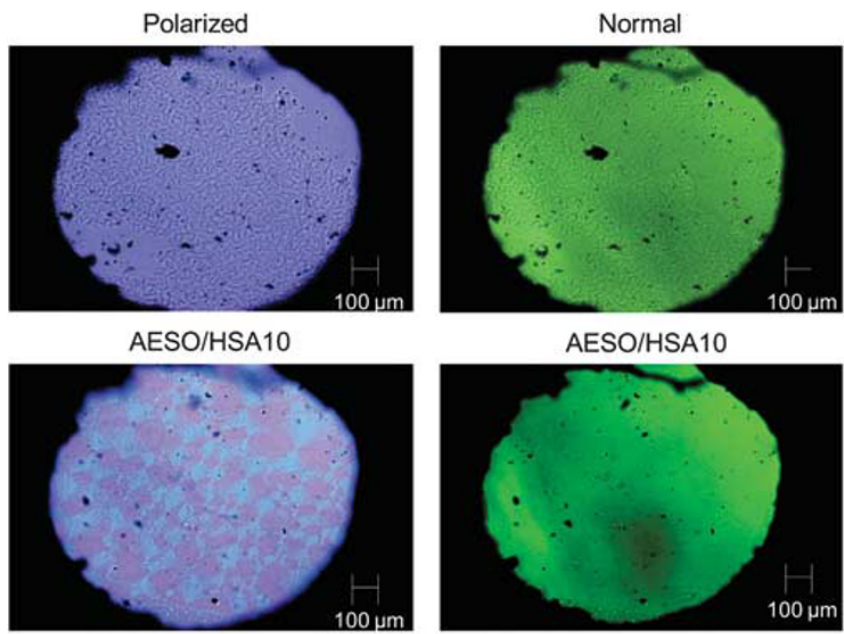

cAESO/HSA10
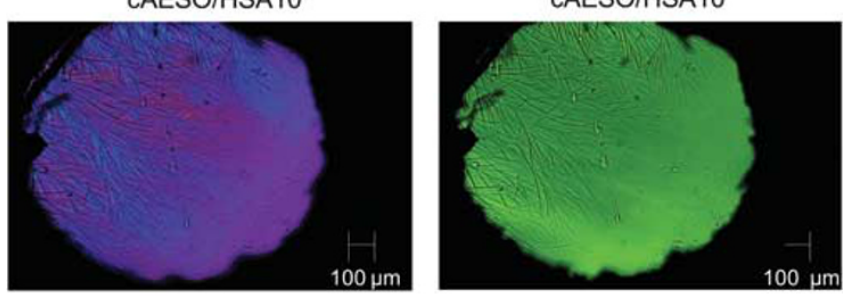

AESO/CIA10

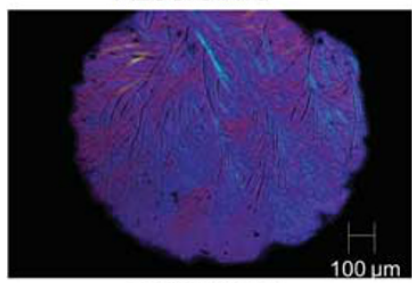

CAESO/CIA10

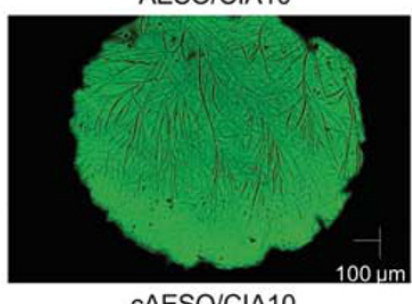

CAESO/CIA10

Figure 7 Polarized and normal optical photomicrographs of acrylated epoxidized soybean oil (AESO/(R)-12-hydroxystrearic acid (HSA)10, crosslinked AESO (CAESO)/HSA1O, AESO/CIA10 and CAESO/CIA10 at room temperature after cooling from $130^{\circ} \mathrm{C}$ at a rate of $-1^{\circ} \mathrm{C} \mathrm{min}-1$.
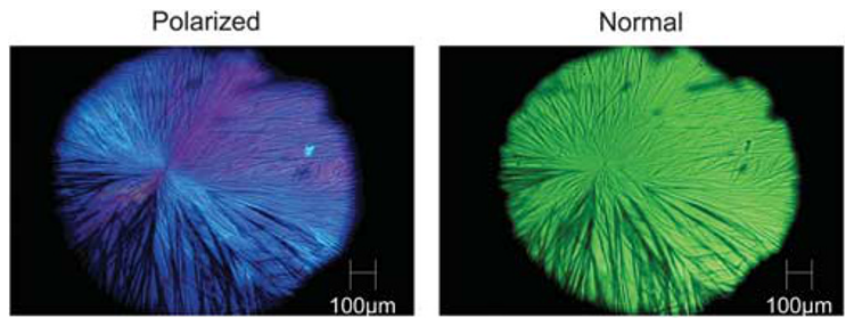

Figure 8 Polarized and normal optical photomicrographs of crosslinked AESO (CAESO)/CIA10 at room temperature after the second cooling from $130{ }^{\circ} \mathrm{C}$ at a rate of $-1{ }^{\circ} \mathrm{C} \mathrm{min}^{-1}$.

between cAESO/CIA and cAESO/HSA. The storage modulus $\left(E^{\prime}\right)$ over the whole temperature range for CAESO/HSA was lower than that for CAESO. In the case of CAESO/CIA, the $E^{\prime}$ below $90^{\circ} \mathrm{C}$, which is near $T_{\mathrm{i}}$ of the CIA mesophase, increased with increasing CIA content. The dynamic mechanical analysis results confirmed the fiber-reinforcement effect of CIA.

Figure 10 shows the flexural strength and modulus at $20^{\circ} \mathrm{C}$ for cAESO/HSA and cAESO/CIA. The flexural strength and modulus of 

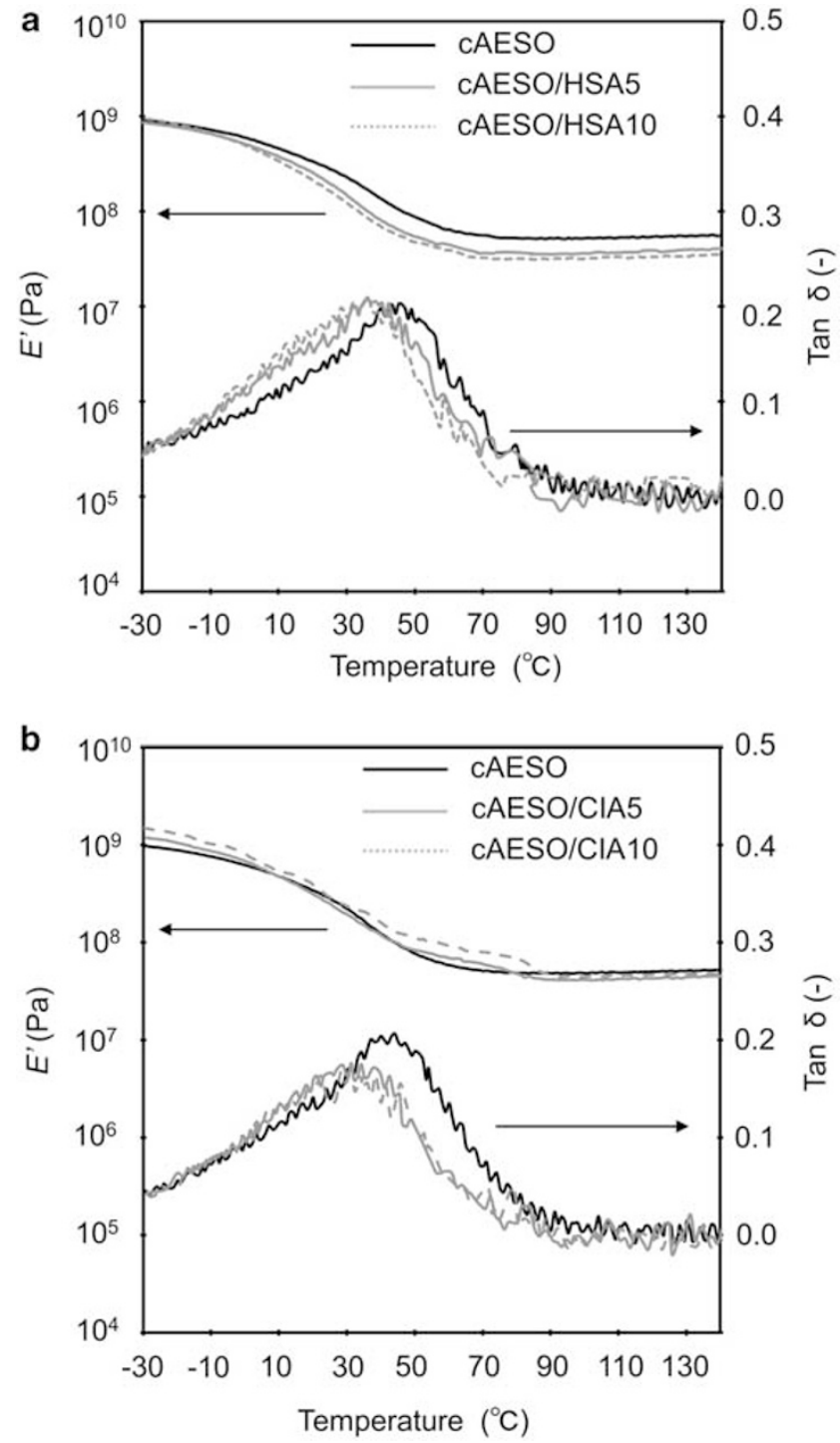

Figure 9 Dynamic mechanical analysis charts of (a) crosslinked AESO (cAESO), cAESO/(R)-12-hydroxystrearic acid (HSA)5 and cAESO/HSA10, and (b) CAESO, CAESO/N-carbobenzyloxy-L-isoleucylaminooctadecane (CIA)5 and $\mathrm{CAESO} / \mathrm{CIA} 10$.

cAESO/CIA increased with increasing CIA content. The improvement in the flexural properties should be related to the formation of a homogeneous three-dimensional fibrous network structure with several physical crosslinking points. In contrast, the flexural strength and modulus of cAESO/HSA decreased with increasing HSA content. These results show that the mechanical properties of the composite are not improved by a heterogeneous crystallization of HSA.

\section{CONCLUSIONS}

A mixture of AESO with 5- to 10-p.h.r. HSA or CIA-containing photoinitiators was heated to $130{ }^{\circ} \mathrm{C}$ and gradually cooled to room temperature to give bio-based AESO/HSA and AESO/CIA gels. The photocuring of the AESO/CIA gel afforded cAESO/CIA in which a self-assembled CIA fibrous network was formed. On the other hand, the photocuring of AESO/HSA gel afforded cAESO/HSA containing crystalline-phase HSA. The $E^{\prime}$ below $T_{\mathrm{i}}$ of the CIA mesophase for cAESO/CIA was higher than that of cAESO. The lowering of the $\tan \delta$
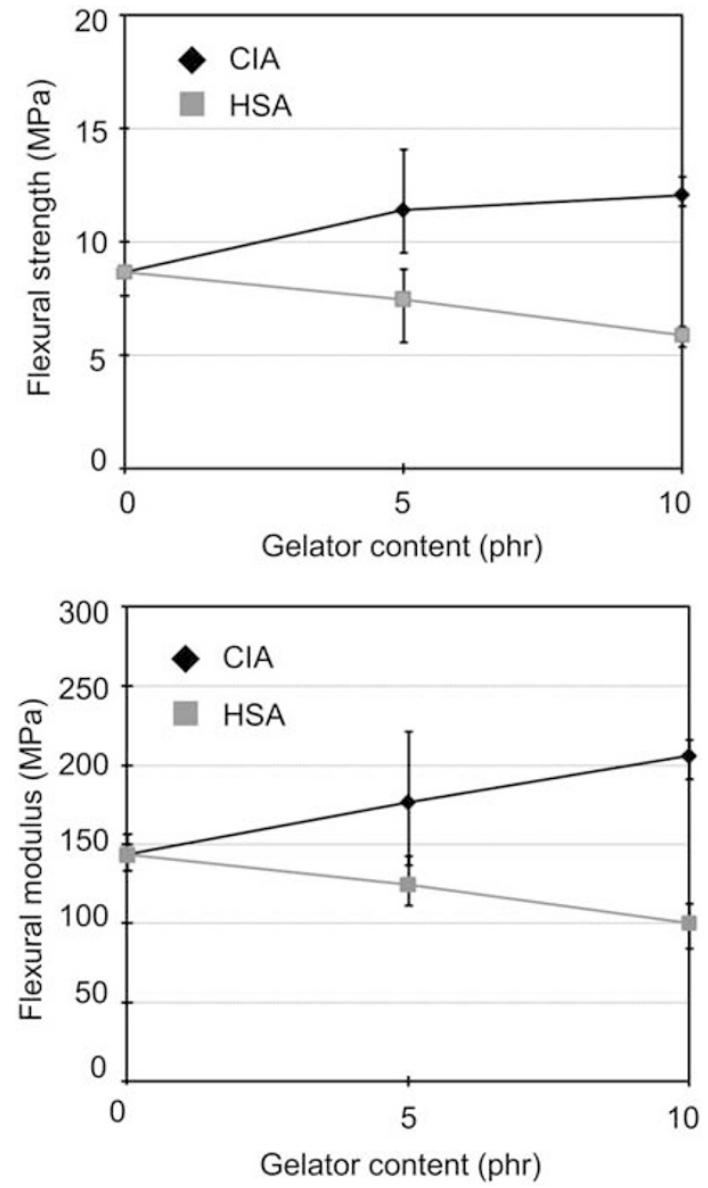

Figure 10 Relationship between flexural properties and gelator content for crosslinked AESO (CAESO)/(R)-12-hydroxystrearic acid (HSA) and CAESO/ $\mathrm{N}$-carbobenzyloxy-L-isoleucylaminooctadecane (CIA).

peak temperature of CAESO/CIA relative to cAESO/HSA was caused by the difference in the dissolved amount in cAESO between CIA and HSA. The tensile strength and modulus at $20^{\circ} \mathrm{C}$ for cAESO/CIA increased with CIA content, whereas those of cAESO/HSA decreased with HSA content. Consequently, the mechanical properties of the cAESO composite were improved by the formation of a fibrous network of CIA, although they were not improved by the heterogeneous crystallization of HSA.

\section{ACKNOWLEDGEMENTS}

This work was supported by KAKENHI (20550194).

1 Kaplan, D. L. in Biopolymers from Renewable Resources (ed. Kaplan, D. L.) Ch. 1, 1-26 (Springer, Berlin, 1998)

2 Mohanty, A. K., Misra, M. \& Hinrichsen, G. Biofibres, biodegradable polymers, biocomposites: an overview. Macromol. Mater. Engn. 276, 1-24 (2000).

3 Mohanty, A. K., Misra, M. \& Drzal, L. T. Sustainable bio-composites from renewable resources: opportunities and challenges in the green materials world. J. Polym. Environ. 10, 19-26 (2002)

4 Biermann, U., Metzger, J. O., Friedt, W., Luehs, W., Lang, S., Machmueller, G., Schneider, M. P., Ruesch, G. K. M. \& Schaefer, H. J. New syntheses with oils and fats as renewable raw materials for the chemical industry. Angew. Chem. Int. Ed. 39, 2206-2224 (2000).

5 Wool, R. P. \& Sun, X. S. in Bio-Based Polymers and Composites (eds. Wool, R. P. \& Sun, X. S.) Ch.4, 56-111 (Academic Press, London, 2005). 
6 Lu, J., Khot, S. \& Wool, R. P. New sheet molding compound resins from soybean oil. I. Synthesis and characterization. Polymer 46, 71-80 (2005).

7 Fu, L., Yang, L., Dai, C., Zhao, C. \& Ma, L. Thermal and mechanical properties of acrylated epoxidized-soybean oil-based thermosets. J. Appl. Polym. Sci. 117, 2220-2225 (2010).

8 Lu, J., Hong, K. \& Wool, R. P. Bio-based nanocomposites from functionalized plant oils and layered silicate. J. Polym. Sci. 42, 1441-1450 (2004).

9 Şen, S. \& Çayli, G. Synthesis of bio-based polymeric nanocomposites from acrylated epoxidized soybean oil and montmorillonite clay in the presence of a bio-based intercalant. Polym. Int. 59, 1122-1129 (2010).

10 Åkesson, D., Skrifvars, M., Lv, S., Shi, W., Adekunle, K., Seppälä, J. \& Turunen, M. Preparation of nanocomposites from biobased thermoset resins by UV-curing. Prog. Org. Coat. 67, 281-286 (2010).

11 O'Donnell, A., Dweib, M. A. \& Wool, R. P. Natural fiber composites with plant oil-based resin. Compos. Sci. Technol. 64, 1135-1145 (2004).

12 Hong, C. K. \& Wool, R. P. Development of a bio-based composite material from soybean oil and keratin fibers. J. Appl. Polym. Sci. 95, 1524-1538 (2005).

13 Åkesson, D., Skrifvars, M. \& Walkenström, P. Preparation of thermoset composites from natural fibers and acrylate modified soybean oil resins. J. Appl. Polym. Sci. 114, 2502-2508 (2009).

14 Wilder, E. A., Wilson, K. S., Quinn, J. B., Skrtic, D. \& Antonucci, J. M. Effect of an organogelotor on the properties of dental composites. Chem. Mater. 17, 2946-2952 (2005).

15 Shibata, M., Teramoto, N., Someya, Y. \& Suzuki, S. Bio-based nanocomposites composed of photo-cured epoxidized soybean oil and supramolecular hydroxystearic acid nanofibers. J. Polym. Sci. 47, 669-673 (2009).
16 Tachibana, T., Mori, T. \& Hori, K. New type of twisted mesophase in jellies and solid films of chiral 12-hydroxyoctadecanoic acid. Nature 278, 578-579 (1979).

17 Tachibana, T., Mori, T. \& Hori, K. Chiral mesophases of 12-hydroxyoctadecanoic acid in jelly and in the solid state. I. A new type of lyotropic mesophase in jelly with organic solvents. Bull. Chem. Soc. Japan. 53, 1714-1719 (1980).

18 Tamura, T., Suetake, T., Ohkubo, T. \& Ohbu, K. Effect of alkali metal ions on gel formation in the 12-hydroxystearic acid/soybean oil system. J. Am. Oil. Chem. Soc. 71, 857-861 (1994).

19 Rogers, M. A., Wright, A. J. \& Marangoni, A. G. Nanostructuring fiber morphology and solvent inclusions in 12-hydroxystearic acid/canola oil organogels. Curr. Opin. Colloid Interface Sci. 14, 33-42 (2009).

20 Fameau, A. L., Houinsou-Houssou, B., Novales, B., Navailles, L., Nallet, F. \& Douliez, J. P. 12-Hydroxystearic acid lipid tubes under various experimental conditions. J. Colloid Interface Sci. 341, 38-47 (2010).

21 Hanabusa, K., Hiratsuka, K., Kimura, M. \& Shiraim, H. Easy preparation and useful character of organoel electrolytes based on low molecular weight gelator. Chem. Mater. 11, 649-655 (1999).

22 Suzuki, M., Sata, T., Kurose, A., Shirai, H. \& Hanabusa, K. New low-molecular weight gelators based on I-valine and I-isoleucine with various terminal groups. Tetrahedron Lett. 46, 2741-2745 (2005).

23 Suzuki, M., Abe, T. \& Hasnabusa, K. Low-molecular-weight gelators based on $N^{\alpha}$-acetyl- $N^{\varepsilon}$-dodecyl-L-lysine and their amphiphilic gelation properties. J. Colloid Interface Sci. 341, 69-74 (2010).

$24 \mathrm{Fu}, \mathrm{X}$., Wang, N., Zhang, S., Wang, H. \& Yang, Y. Formation mechanism of supramolecular hydrogels in the presence of L-phenylalanine derivative as a hydrogelator. J. Colloid Interface Sci. 315, 376-381 (2007). 